\title{
The Effect of Mix-Design and Corrosion Inhibitors on the Durability of Concrete
}

\author{
Loukas Karavokyros1, Nikolaos Katsiotis', Emmanouil Tzanis², George Batis1, \\ Andreas Sapalidis ${ }^{3}$, Alexandros Chatzopoulos ${ }^{4}$, Kosmas Sideris4, Margarita Beazi-Katsioti1
}

\author{
${ }^{1}$ National Technical University of Athens, School of Chemical Engineering, NTUA Zografou Campus, \\ Athens, Greece \\ ${ }^{2}$ Titan Cement Group, Athens, Greece \\ ${ }^{3}$ Institute of Nanoscience and Nanotechnology, National Center for Scientific Research "Demokritos", \\ Athens, Greece \\ ${ }^{4}$ Democritus University of Thrace, Department of Civil Engineering, Laboratory of Building Materials, Kimmeria Univesity \\ Campus, Xanthi, Greece \\ Email: loukas.kara@gmail.com
}

How to cite this paper: Karavokyros, L., Katsiotis, N., Tzanis, E., Batis, G., Sapalidis, A., Chatzopoulos, A., Sideris, K. and Beazi-Katsioti, M. (2020) The Effect of MixDesign and Corrosion Inhibitors on the Durability of Concrete. Journal of Materials Science and Chemical Engineering, 8, 64-77.

https://doi.org/10.4236/msce.2020.84005

Received: March 25, 2020

Accepted: April 21, 2020

Published: April 24, 2020

Copyright ( 2020 by author(s) and Scientific Research Publishing Inc. This work is licensed under the Creative Commons Attribution International License (CC BY 4.0).

http://creativecommons.org/licenses/by/4.0/ (c) (i) Open Access

\begin{abstract}
The deterioration of concrete over time is the result of various mechanical, physical, chemical and biological processes, with the corrosion of reinforcement being the most serious problem of durability of reinforced concrete structures. Over the last 50 years, a tremendous effort has been spent by the international scientific community with laboratory research and experimental field studies in order to increase the resistance of concrete over corrosion. This paper presents an experimental study of the corrosion behavior of 5 different concrete mix designs. The compositions were developed as per the latest concrete regulations and International Standards which are as follows: conventional concrete $\mathrm{C} 30 / 37$, conventional concrete with corrosion inhibitor as an additive, conventional concrete with surface spray sealant, fine aggregate concrete and self-compacting concrete. Their behavior against corrosion was determined via the following tests: water absorption test, water permeability test, mercury intrusion porosimetry, rapid chloride penetration test (RCPT), and accelerated carbonation test. The experimental results showed that the corrosion systems examined in the study provide anti-corrosion protection on steel rebars against corrosion comparing with the reference group. Also, an inversely proportional relationship of the water/cement ratio of a composition with its corrosion behavior was observed. Smaller w/c values (0.4 instead of 0.5$)$ lead to better anti-corrosion resistance. In addition, an analogous relationship between the cement content of a composition and its corrosion behavior was observed.
\end{abstract}




\section{Keywords}

Reinforced Concrete, Carbonation, Corrosion Inhibitor, Mercury Intrusion Porosimetry, Chloride Ion

\section{Introduction}

In recent years, there have been intense problems of unsatisfactory results in structural durability, with corrosion of reinforcement being the most important problem in reinforced concrete structures. The chloride-induced steel corrosion in reinforced concrete structures (RCS) in marine environments is of major concern. In general, the high alkalinity of concrete pore solutions leads to a protective passive film on the steel surface which delays corrosion initiation. However, when the content of chloride ions at the steel-concrete interface reaches the chloride threshold level, steel starts to corrode and corrosion products are generated gradually on the steel surface, ultimately leading to premature cracking and spalling of RCSs [1]. The most widely used protective methods for the effective protection of the steel reinforcement in concrete structures, are the following: cathodic protection, organic coatings, corrosion inhibitors and mineral additives such as pozzolans, silica fume etc. [2]. Corrosion inhibitors are organic or inorganic salts used as admixtures in concrete production in order to protect the steel rebars from the corrosion; on the other hand, the inhibitors improve the chloride penetration resistance of concrete. A corrosion inhibitor can be defined as "a chemical compound" added in adequate amounts to concrete which prevents or delays the corrosion of embedded steel and has no adverse effect on its physical/mechanical properties. It is worth noting that these types of admixtures increase the consistency of the passive layer on the steel surface, creating a barrier film on the steel, blocking the ingress of chlorides and increasing the degree of chloride binding capacity of the concrete; the oxygen ingress can be also prevented using the corrosion inhibitors [2] [3]. In previous work, it has been proved that the organic coatings can also be used for the protection of the steel reinforcement, as they consist of a barrier between the porous concrete structure and the corrosive environment and so they are widely used in concrete structures for corrosion protection [4]. In this paper, the main objective is the experimental study of different utilization of corrosion inhibitors, either as an additive or as a spray and the possibility of protection that a corrosion inhibitor can provide. Also, a comparison was made between compositions with lower w/c ratio as well as increased cement content with the reference composition. To determine the degree of protection of the corrosion inhibitor by different application modes (additive, spray) as well as the effect of the different components of the specimens, several cube and cylindrical specimens were manufactured to be tested in the laboratory tests to evaluate their anti-corrosion behavior. These samples' degree of protection was determined via the following tests: water ab- 
sorption test, water permeability test, mercury intrusion porosimetry, rapid chloride penetration test (RCPT), and accelerated carbonation test.

\section{Materials and Methods}

\subsection{Materials}

The tested concrete compositions were selected following the limitations set by the latest concrete technology regulations and are the following: conventional concrete (cc) of quality C30/37 (titled CC1), cc with additional corrosion inhibitor $4 \% \mathrm{w} / \mathrm{w}$ of cement (titled CC2), cc with surface sprayed sealant (titled CC3), self-compacting concrete (titled SCC) and fine aggregate concrete (titled FAC) with the absence of large coarse aggregate $(\mathrm{dmax}<16 \mathrm{~mm})$. All concrete compositions were prepared in a ready-mix concrete plant. The mix designs that were examined can be divided into two groups based on their composition. The first group consists of the first 3 concrete compositions (CC1, CC2, CC3) that are based on the C30/37 quality mix design and the second group (FAC, SCC) consists of the compositions with finer mix arrangements (absence of coarse aggregate, Dmax $<16 \mathrm{~mm})$, as well as lower $\mathrm{w} / \mathrm{c}$ and higher cement content $\left(\mathrm{kg} / \mathrm{m}^{3}\right)$. A commercial AMA (amino alcohol) based corrosion inhibitor is used. As the main component of an AMA-based inhibitor, amino alcohol rapidly migrates into concrete in the gas phase or liquid phase. When it reaches the surface of the steel bar, it forms a hydrophobic monomolecular layer by physical or chemical adsorption. The molecule isolates chloride ion, oxygen, and water and protects the reinforcement [5] [6]. The surface inhibitor was applied in two hands coatings on all sides of the specimens according to the manufacturer's recommended dose $\left(200 \mathrm{~g} / \mathrm{m}^{2}\right)$. The two comparative states studied are as follows: one in terms of the effect of corrosion inhibitors on the concrete (CC1, CC2, CC3) and one in the mixture proportions of the compositions (CC1, FAC, SCC).

\subsection{Mixture and Preparation of Concrete Specimens}

Five groups of specimens were constructed and each one of them consisted of 14 cube specimens with an edge of a $100 \mathrm{~mm}$ and 2 cylindrical specimens with a height of $100 \mathrm{~mm}$ and a diameter of $50 \mathrm{~mm}$ for a total of 70 cube and 10 cylindrical specimens. The specimens were cured under a temperature of $20^{\circ} \mathrm{C} \pm 3^{\circ} \mathrm{C}$ and a relative humidity $\mathrm{RH} \geq 90 \%$ for 28 days. The mixture proportions ratio (cement:water:sand:fine aggregate:coarse aggregate) were as follows (by weight):

- $\quad$ reference concrete $(\mathrm{CC})=1: 0.5: 3: 3: 2.8$.

- $\quad$ SCC $=1: 0.40: 2 \cdot 1: 2 \cdot 1: 1.1$.

- fine aggregate concrete $(\mathrm{FAC})=1: 0.48: 2.5: 3 \cdot 2: 1.2$.

The mixture proportions of concrete specimens that were used are given in the following table (Table 1). Sand with fineness modulus of 2.40 and fine gravel (4-8 $\mathrm{mm}$ ) were used as fine aggregates. Gravel $(>8 \mathrm{~mm}$ ) was used as coarse aggregate, respectively. The binding material of the concrete specimens is Ordinary Portland Cement. 
Table 1. Mixture proportions of produced concretes.

\begin{tabular}{cccccc}
\hline$\left(\mathrm{kg} / \mathrm{m}^{3}\right)$ & $\mathrm{CC} 1$ & $\mathrm{CC} 2$ & $\mathrm{CC} 3$ & FAC & SCC \\
\hline Cement & 330 & 330 & 330 & 400 & 500 \\
water & 165 & 165 & 165 & 200 & 200 \\
w/c ratio & 0.5 & 0.5 & 0.5 & 0.5 & 0.4 \\
Fine Agg. & 975 & 975 & 975 & 1260 & 1050 \\
Coarse Agg. & 930 & 930 & 930 & 495 & 570 \\
Super/zer & 2 & 2 & 2 & 3.5 & 5.5 \\
Inhibitor & - & 13.2 & - & - & - \\
Slump (cm) & 3 & 4 & 3 & 5 & 60 (flow) \\
Fc, 28 (Mpa) & 45.3 & 43.1 & 45.1 & 52.5 & 56 \\
\hline
\end{tabular}

Subsequently, a detailed description of the methods used in this paper to evaluate the properties of the compositions associated with their anti-corrosion behavior is presented.

\subsection{Capillary Water Absorption}

Chloride in concrete moves in three pathways: diffusion, capillary absorption, and penetration. Diffusion is caused by the concentration gradient in concrete's pores. Capillary absorption is caused by the capillary pressure of the fluid's surface. In penetration, the transport of water is governed by factors like pore connectivity and pore size distribution, other than water accessible porosity, indicating that pozzolanic reaction can refine the capillary pores for water [7]. The results of the capillary absorption test showed that the inhibitor can prevent chloride penetration in concrete by suppressing capillary absorption. However, the proportion of the macropores and capillaries increases the water/cement ratio increases. The pore-blocking effect may weaken, and the effect of chloride resistance may decrease for the same dosage of inhibitor. Studies show that the inhibitor Dimethylethanolamine (AMA) can replace the chloride ion on the surface of a rebar and form a stable layer [8] [9]. However, the actual concentration of AMA that reaches the depth of steel bars is relatively low. In many cases, a continuous film cannot be formed. The method used to determine the water absorption of the tested compositions was conducted according to the ASTM C1543 standard [10]. After curing for 28 days, 3 cube specimens of each group with a height of $100 \mathrm{~mm}$ were placed in an oven for 72 hours to remove the moisture. On removal, each specimen was cooled for 24 hours in the dry airtight vessel. The mass of each specimen was recorded immediately after the cooling process. All specimens were completely immersed in a tank for $30 \mathrm{~min}$ with its longitudinal axis horizontal and at a depth at which there is $25 \mathrm{~mm}$ of water above the top of the specimen. Upon removal, each specimen was cleaned to remove the bulk of the surface and dried with a cloth as rapidly as possible until all free water was removed from the surface. Then the mass was determined by an electronic balance to identify the amount of water absorbed. The measured 
absorption of each specimen is calculated as the increase in mass resulting from immersion expressed as a percentage of the mass of the dry specimen. A correction factor according to the surface to volume ratio of the specimen shall be obtained using the following formula (Equation (1)):

$$
\text { correction factor }=\frac{\operatorname{volume}\left(\mathrm{mm}^{3}\right)}{\text { surface area }\left(\mathrm{mm}^{2}\right) \times 12.5} \text {. }
$$

\subsection{Water Permeability}

The method used to determine the water permeability of the tested compositions was conducted according to EN12390. Factors that are known to affect chloride ion penetration include w/c ratio, the presence of polymeric admixtures, sample age, air-void system, aggregate type, degree of consolidation and type of curing. All groups' specimens were tested at 28 days. In each case, the specimen was placed in the apparatus and a water pressure of $500 \mathrm{kPa}$ was applied for $72 \mathrm{hrs}$ (Figure 1). During the test, the appearance of the surfaces of the test specimen not exposed to the water pressure was observed periodically to note the presence of water.

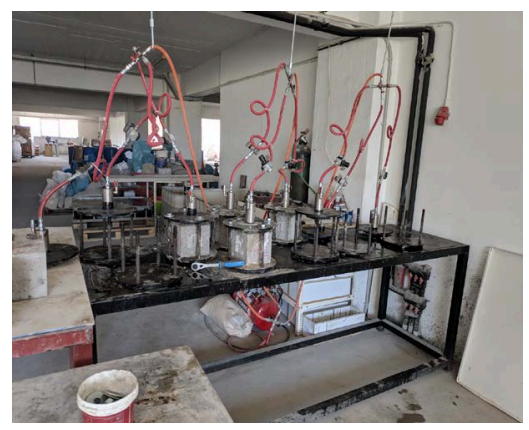

(a)
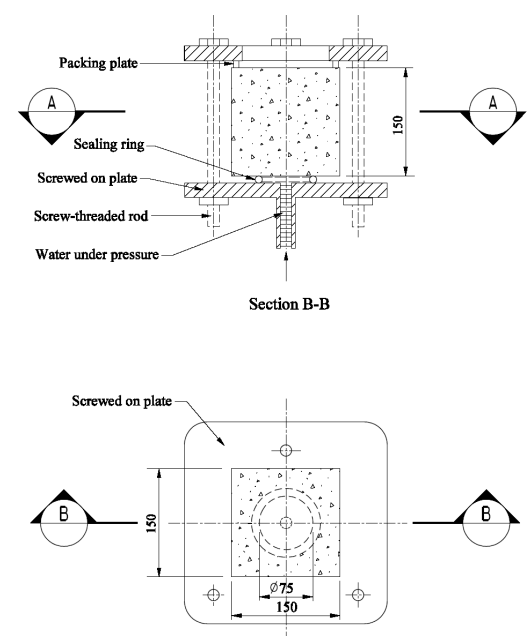

Section A-A

(b)

Figure 1. (a) photo of the apparatus for determining the penetration of water, (b) side view and overview of the apparatus. 
After the pressure was applied for the specified time, the specimen was removed from the apparatus. The face on which the water pressure was applied was wiped to remove excess of water. The specimen was then split in half, perpendicularly to the face on which the water pressure was applied. When splitting the specimen, and during the examination, the face of the specimen exposed to the water pressure was placed on the bottom as dictated [11]. As soon as the split face has dried to such an extent that the water penetration front could be seen, the water front on the specimen was marked. The maximum depth of penetration under the test area was then measured and recorded to the nearest millimeter. The penetration depth was determined by the following equation:

$$
P=\frac{D_{1}+D_{2}+\cdots+D_{n}}{n}
$$

where $P$ is the average depth, $D_{n}$ is the depth of testing specimens in $\mathrm{mm}$, and $n$ is the number of testing specimens.

\subsection{Rapid Chloride Permeability Test (RCPT)}

The chloride permeability test was conducted according to the ASTM C1202 standard (EN 13396). The rapid chloride permeability test is commonly used to evaluate the resistance of concrete to chloride ions ingress owing to its simplicity and rapidity the ASTM C1202 test provides an indication of concrete resistance to the penetration of chloride ions. The more permeable is the concrete, the more negative ions will migrate through the specimen, and a higher current will be measured. The correlations between the results of this test (charged passed) and the long-term chloride penetrability of concrete established by ASTM C1202 are presented in Table 2 [12].

All specimens were demolded at $24 \mathrm{~h}$ and moist cured at $23^{\circ} \mathrm{C}$ and $95 \% \mathrm{RH}$ for 28 days. Concrete disks of $100 \mathrm{~mm}$ in diameter and $50 \mathrm{~mm}$ in thickness were sliced from the top portion of $100 \mathrm{~mm} \times 200 \mathrm{~mm}$ cylinders for the RCPT. Two samples were prepared for each mixture. Samples were preconditioned according to the ASTM C 1202 standard procedure. The anolyte solution $(\mathrm{NaOH})$ concentration was at $0.3 \mathrm{~N}$ and the concentration of the catholyte solution $(\mathrm{NaCl})$ was $3 \%$ as per the ASTM C 1202 guidelines (Standard Test Method for Compressive Strength of Cylindrical Concrete Specimens). According to the ASTM C 1202, a 60 V DC was applied for 6 hours or until high temperature of

Table 2. Chloride ion penetrability based on charge passed (ASTM C1202).

\begin{tabular}{cc}
\hline Chloride Penetration & $\begin{array}{c}\text { Rapid Chloride Permeability Charge Passed as per } \\
\text { ASTM C1202 (Coulombs) }\end{array}$ \\
\hline High & $>4000$ \\
Moderate & $2000-4000$ \\
Low & $1000-2000$ \\
Very Low & $100-1000$ \\
Negligible & $<100$ \\
\hline
\end{tabular}




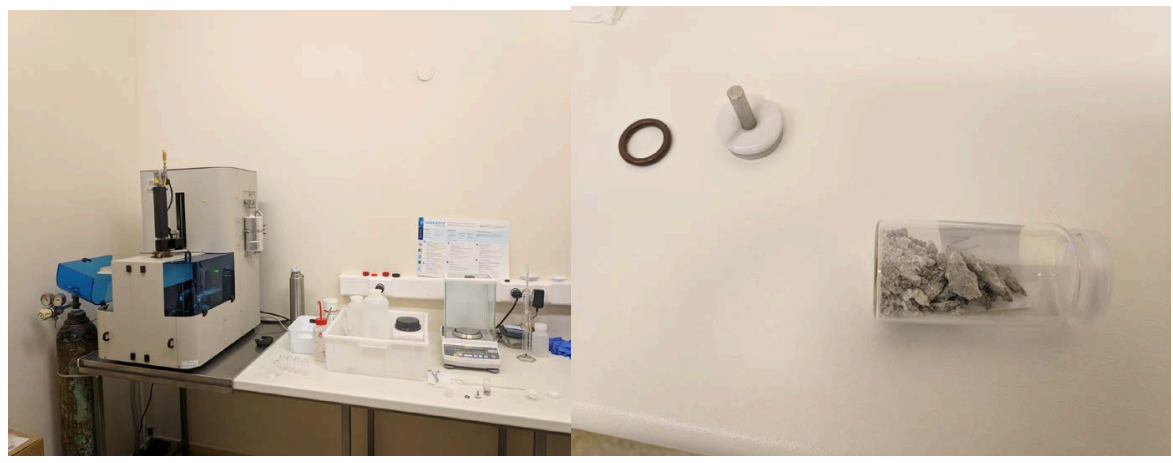

Figure 2. Left: apparatus for mercury intrusion porosimetry testing; Right: sample for testing.

solutions is observed. The PROOVE'it apparatus by German Instruments was used to evaluate the resistance of concrete to the ingress of chloride ions by determining the total electrical charge that passes through a saturated concrete specimen by applying an electrical potential across the specimen. This is known as the "Coulomb Test" or the "Rapid Chloride Permeability Test".

\subsection{Accelerated Carbonation}

Carbonation is one of the major factors causing structural deterioration. Carbonation is the reaction of the hydration products dissolved in the pore water with the carbon dioxide in the air which reduces the $\mathrm{pH}$ of concrete pore solution from 12.6 to less than 9 and steel passive oxide film may be destroyed and accelerating uniform corrosion [13]. Carbonation-induced corrosion can increase crack development and decrease concrete durability [14].

The $100 \mathrm{~mm}$ cube specimens were cast according to the five mixture proportions and then preconditioned by oven drying $\left(60^{\circ} \mathrm{C}\right)$ for $48 \mathrm{~h}$ to obtain a low moisture content value. The cube specimens were placed in a carbonation chamber. The concentration of $\mathrm{CO}_{2}$ was maintained at $1 \% \pm 0.1 \%$. The other conditions were $55 \% \pm 5 \%$ relative humidity and $20^{\circ} \mathrm{C} \pm 1{ }^{\circ} \mathrm{C}$ temperature as per EN 13295 [15]. At 60 and 120 days, the concrete specimens were split in the lateral direction. A phenolphthalein solution (alcohol concentration of $1 \%$, distilled water concentration of $20 \%$ ) was sprayed on the cross-section. The carbonation depth of concrete was determined by the following equation:

$$
X_{p}=\frac{A_{1}+A_{2}+\cdots+A_{n}}{n}
$$

where $X_{p}$ is the average carbonation depth, $A_{n}$ is the depth of testing points, and $n$ is the number of testing points [16].

\subsection{Mercury Intrusion Porosimetry}

For the mercury intrusion porosimetry testing, small cores were carefully drilled out, to minimize coarse aggregates inclusion, from the middle of the cube samples weighting approximately $0.8 \mathrm{~g}$ and sizing $5.5 \mathrm{~mm}$, to determine the pore size distribution and average porosity for the tested mixtures as shown in Figure 2 
[17]. The experiments were performed at a Quantachrome Poremaster ${ }^{\circledast}$ porosimeter, shown in Figure 2. For each mixture, two samples were tested to obtain statistically representative average results. Preconditioning of samples was done by oven drying at $60^{\circ} \mathrm{C} \pm 5^{\circ} \mathrm{C}$ until a constant mass to reduce the potential of drying shrinkage cracks associated with higher temperatures. The apparatus had a pressure range from sub-ambient to $413 \mathrm{MPa}$. By assuming a cylindrical geometry of pores, a mercury contact angle of $140^{\circ}$ and a surface tension of 0.471 $\mathrm{N} / \mathrm{m}$, the high-pressure limit (413 MPa) yields a pore radius of $3.6 \mathrm{~nm}$, implying intrusion of all capillary pores since the smallest size of capillary pores reported in the literature is about $5 \mathrm{~nm}$ to $20 \mathrm{~nm}$ [18]. Most of the CSH gel pores cannot be intruded under such pressure; however, such pores have little, if any, contribution to mass transport mechanisms in the concrete matrix.

\section{Results and Discussion}

\subsection{Capillary Water Absorption Test}

The water absorption test results are shown in Figure 3. The main transportation mode of water in concrete is capillary absorption. Absorption ability mainly depends on the microstructure. The inhibitor can block the pores (generally micropores and capillaries) of concrete and change the microstructure of concrete; therefore, concrete resistance to water absorption is improved. However, as the water/cement ratio is increased, the porosity of concrete is also increased. More capillaries and macropores may exist because of the porosity of concrete.

The water absorption coefficients of the treatment group were lower compared with those of the control group. The porosity of concrete was changed after the application of the inhibitor, and the pore-blocking effect improved water resistance. Also, the decrease in water/cement ratio reduced the effect as is clearly evident from the SCC results. It is also observed that in both of these categories (CC2, CC3, and FAC, SCC) the behavior is similar as all values are of similar magnitude $(0.22 \%-0.24 \%)$.

\subsection{Water Permeability Test}

After the pressure was applied for the specified time, the specimen was removed

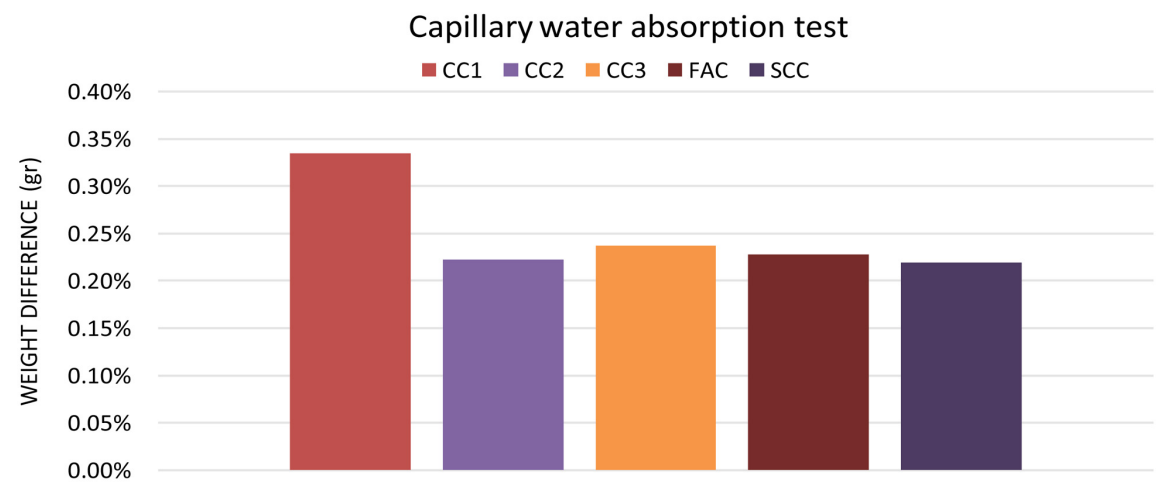

Figure 3. Capillary water absorption test results. 
from the apparatus. The specimen was then split in half, perpendicularly to the face on which the water pressure was applied and the maximum depth of penetration under the test area was measured and recorded to the nearest millimeter. The results for all tested compositions are given in Figure 4.

The inhibitor can generally block the pores and change the microstructure of concrete; although as it is observed from Figure 4, the penetration depth of the specimens with inhibitor ( 29.3 and $30.7 \mathrm{~mm}$ ) is close to the results observed at the reference specimen $(32.7 \mathrm{~mm})$. Taking into consideration the results of the capillary water absorption test it is observed that corrosion inhibitors prevent the penetration of the water when it uses the capillary network. However, when water penetrates the interior of the element under pressure, the inhibitors show an inability to contain it by presenting values similar to those of the reference concrete. On the other hand, the two mix designs with more cement in their compositions (FAC and SCC) exhibit improved behavior (20 and $8 \mathrm{~mm}$ respectively). Especially in the case of SCC, it is clearly observed that lower w/c ratio leads to a strong resistance to pressurized water as the lowest penetration depth $(8 \mathrm{~mm})$ is observed.

\subsection{Chloride Permeability Test}

As described, the ASTM C1202 (EN 13396) test provides an indication of concrete resistance to the penetration of chloride. The correlations between the results of this test (charged passed) and the long-term chloride penetrability of concrete established by ASTM C1202 are presented in Table 2. The RCPT results for all tested compositions, are shown in Figure 5. The test lasted for $6 \mathrm{~h}$ or until solutions reached a high temperature of $80^{\circ} \mathrm{C}$, which was defined as an upper limit to avoid damage of test cell compartments [12]. Figure 5 shows that the ultimate recorded passing charges ranged from 2204 to 2532 Coulombs, which correspond to moderate chloride penetrability, according to the ASTM C1202 (Table 2).

From Figure 5, it is observed that the electrical resistivity for mixtures with corrosion protection (CC2, CC3) increased, resulting in lower passing charges

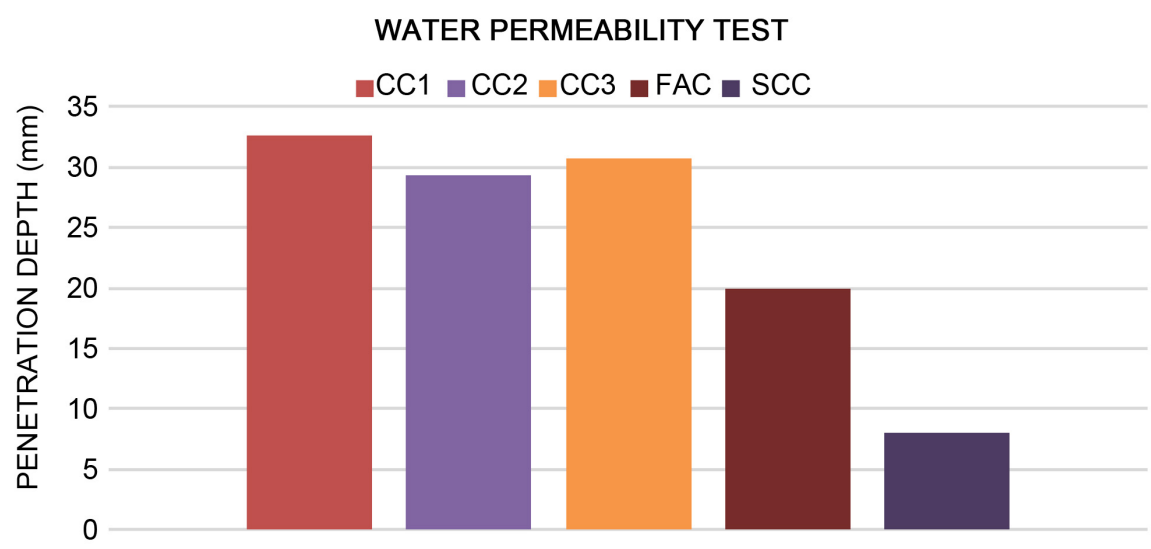

Figure 4. Water Permeability results for each tested composition. 


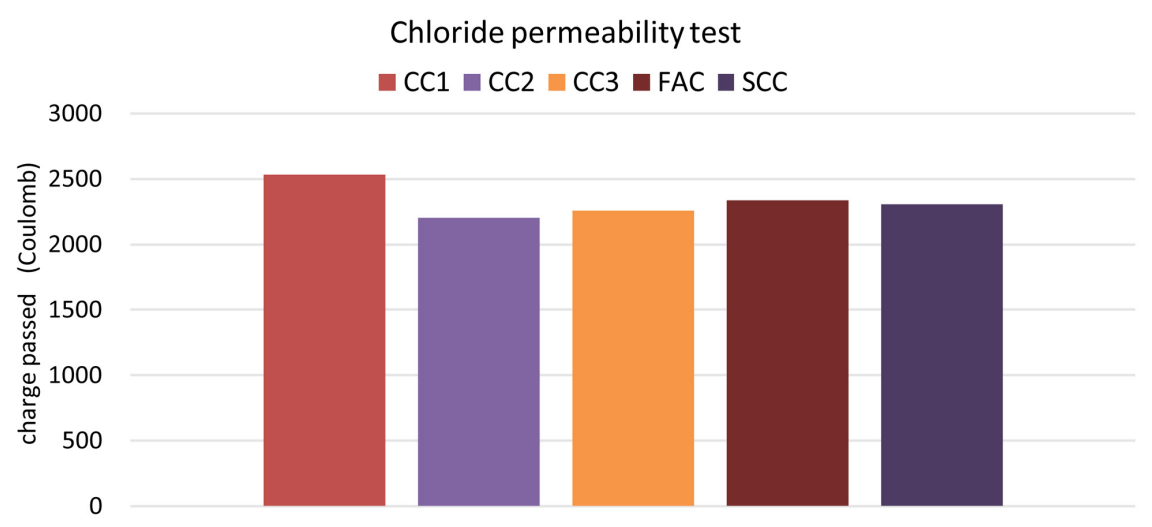

Figure 5. RCPT results for each tested composition.

but not to a great extent. The same behavior is observed at the FAC and SCC as charge passed values are to the same extent as in CC2 and CC 3 and therefore have similar electrical resistivity. Finally, it is observed that all charge values obtained from the RCPT test are between 2000 and 4000 Coulombs and so the chloride penetration depth to all tested compositions are classified as moderate.

\subsection{Accelerated Carbonation Test}

All tested cube specimens remained in the carbonation chamber under the previously described conditions for 60 and 120 days. After these ages, they were removed from the chamber and spitted in two pieces. The depth of carbonation at every age was estimated as the mean value of the carbonation depth measured in two cubic specimens. The carbonation depth of the concrete specimens treated with the inhibitor as an additive-CC2 $(6.1 \mathrm{~mm}, 6.9 \mathrm{~mm})$ or in sprayed form-CC3 $(4.1 \mathrm{~mm}, 5.2 \mathrm{~mm})$ was lower than that of the control specimens-CC1 $(8.8 \mathrm{~mm}, 10.1 \mathrm{~mm})$ as shown in Figure 6.

The concrete specimens treated with inhibitor displayed effective carbonation resistance in both 60 and 120 days. Therefore, the inhibitor positively affected the carbonation resistance of the concrete specimens. To some extent, the pore-blocking property of the AMA-based inhibitor applied on the surface of concrete suppressed the spread of $\mathrm{CO}_{2}$ in concrete. However, this effect was relatively reduced to those specimens with a lower w/c ratio (SCC). Finally, the greatest resistance behavior was observed in specimens with the surface applied corrosion inhibitor (CC3) as well as in Self Compacting Concrete (SCC) as they showed the lowest values in both ages.

\subsection{Mercury Intrusion Porosimetry}

Mercury intrusion experiments were performed at a Quantachrome Poremaster porosimeter. The equivalent pore radius $r$ is computed according to the capillary pressure Washburn equation (Equation (4)):

$$
r=\frac{2 \gamma \times \cos \Theta}{P_{c}}
$$




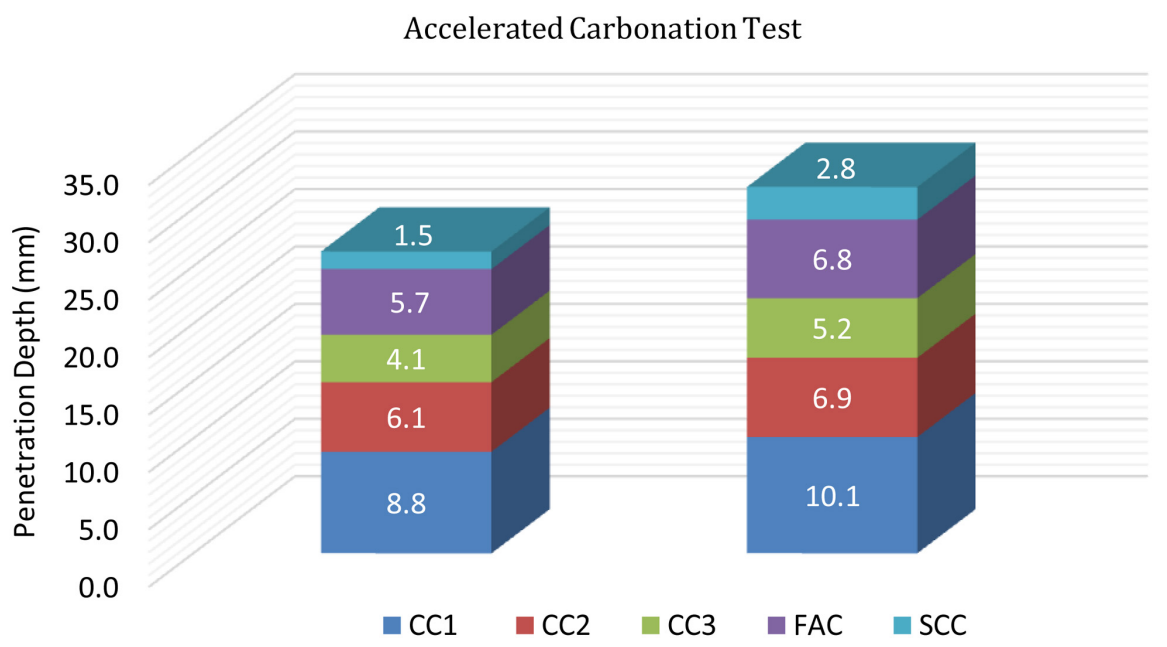

Figure 6. Accelerated carbonation depth results for each tested composition (60 and 120 days in chamber).

Table 3. Results obtained for mercury porosimetry for tested compositions.

\begin{tabular}{ccccc}
\hline Sample & $\begin{array}{c}\text { Bulk density } \\
(\mathrm{g} / \mathrm{cc})\end{array}$ & $\begin{array}{c}\text { Skeletal density } \\
(\mathrm{g} / \mathrm{cc})\end{array}$ & $\begin{array}{c}\text { Intraparticle } \\
\text { Porosity }\end{array}$ & $\begin{array}{c}\text { Total intruded volume } \\
(\mathrm{cc} / \mathrm{g})\end{array}$ \\
\hline CC1 & 2.2997 & 2.5308 & $8.79 \%$ & 0.0397 \\
$\mathrm{CC} 2$ & 2.2257 & 2.4628 & $9.25 \%$ & 0.0433 \\
FAC & 2.4287 & 2.5510 & $7.24 \%$ & 0.0197 \\
SCC & 2.3335 & 2.4750 & $8.70 \%$ & 0.0437 \\
\hline
\end{tabular}

where $P_{c}$ is the capillary pressure $(\mathrm{Pa}), \gamma$ the interfacial tension $(\mathrm{N} / \mathrm{m}),\left(\gamma_{\mathrm{Hg} / \text { air }}=\right.$ $0.471 \mathrm{~N} / \mathrm{m}), r$ is the pore radius, and $\Theta$ the wetting angle $\left(\Theta_{\mathrm{Hg} / \text { air }}=140^{\circ}\right)$. Concrete specimens were taken from the middle of the sample weighting approximately $0.8 \mathrm{~g}$ and sizing $5.5 \mathrm{~mm}$ was used for all the experiments omitting aggregates, and measured without any treatment [17] [19]. Table 3 summarizes results obtained for mercury porosimetry for all tested samples.

It is observed from the table above, that sample from CC3 composition was not included in the test as the surface inhibitor does not affect the porosity of the material. That is because the sample was extracted from the interior of the cube specimen and so the surface applied inhibitor does not influence the porosity results. In specimens CC1, CC2 and SCC similar porosity values of $8.70 \%$ to $9.25 \%$ are observed. The exception was in fine aggregate concrete where a relatively reduced intraparticle porosity value was observed (7.24\%). This is most likely due to the microstructure of this composition since it contains aggregates of all fractions thus creating a more uniform structure that does not allow easily the formation of pores. Finally, another observation that can be made is that the density of all the tested compositions, as calculated from the procedure above, exhibits similar values with the ones that had been calculated during the manufacture of the compositions. 


\section{Conclusions}

In this paper, the corrosion behavior of different concrete compositions and different protection methods was investigated. The following conclusions can be drawn:

1) The surface-applied corrosion inhibitor blocks the pores on the surface of the concrete. Transportation of water, chloride ion, and carbon dioxide into concrete is inhibited; thus, the durability of concrete is improved. Unlike surface-applied corrosion inhibitor, the additive inhibitor cannot form a protective layer on the surface of concrete, and its effect is limited to the microstructure of concrete. Although the surface-applied corrosion inhibitor can improve the durability of concrete, this effect may weaken with time.

2) An inversely proportional relationship of the water/cement ratio of a composition with its corrosion behavior was observed. Smaller w/c values $(0.4$ as opposed to 0.5 ) lead to better anti-corrosion resistance as observed from all tests performed.

3) An analogous relationship between the cement content of a composition and its corrosion behavior was observed. In particular, the increase of cement leads to greater anticorrosion behavior. This was noticed in almost all tests but especially in the water permeability test where the SCC composition had by far the lowest values ( $8 \mathrm{~mm}$ of water penetration).

4) Corrosion inhibitors either as additives or in sprayed form show an increase in the life expectancy of a structure but not to a great extent. Specifically, the specimens with corrosion inhibitors showed improved anticorrosion behavior compared to the reference specimen. Especially at the accelerated carbonation test as well as at the capillary water absorption test the corrosion inhibitors shown great protection abilities.

5) Mix designs that improve corrosion resistance are not substantially different from the proportions of good quality concrete. Low w/c ratios, as well as increase cement content $\left(\mathrm{kg} / \mathrm{m}^{3}\right)$ in concrete composition leads to better anticorrosion resistance without the need to use other protection methods (inhibitors, coatings, etc.).

\section{Acknowledgements}

The authors wish to sincerely thank KOUROS Concrete Company and especially Mr. Elias Katsafados, Directing Manager, for his contribution to the research.

\section{Conflicts of Interest}

The authors declare no conflicts of interest regarding the publication of this paper.

\section{References}

[1] Liu, Z., Miao, C., Zhou, W., and Liu, J. (2008) Maintenance and Improvement of Durability of Reinforced Concrete Using Migrating Corrosion Inhibitors. Journal of 
the Chinese Ceramic Society, 36, 1494-1500.

[2] Xu, Y. (2002) Migrating Corrosion Inhibitor: A New Development of Corrosion Inhibitors for Steel Bar in Concrete. Journal of the Chinese Ceramic Society, 30, 94-101.

[3] Söylev, T.A., McNally, C. and Richardson, M.G. (2007) The Effect of a New Generation Surface-Applied Organic Inhibitor on Concrete Properties. Cement and Concrete Composites, 29, 357-364. https://doi.org/10.1016/j.cemconcomp.2006.12.013

[4] Tritthart, J. (2003) Transport of a Surface-Applied Corrosion Inhibitor in Cement Paste and Concrete. Cement and Concrete Research, 33, 829-834. https://doi.org/10.1016/S0008-8846(02)01067-0

[5] Söylev, T.A., McNally, C. and Richardson, M. (2007) Effectiveness of Amino Alcohol-Based Surface-Applied Corrosion Inhibitors in Chloride-Contaminated Concrete. Cement and Concrete Research, 37, 972-977. https://doi.org/10.1016/j.cemconres.2007.03.010

[6] Morris, W. and Vázquez, M. (2002) A Migrating Corrosion Inhibitor Evaluated in Concrete Containing Various Contents of Admixed Chlorides. Cement and Concrete Research, 32, 259-267. https://doi.org/10.1016/S0008-8846(01)00669-X

[7] Resin, R., Alwared, A. and Al-Hubboubi, S. (2018) Utilization of Brick Waste as Pozzolanic Material in Concrete Mix. MATEC Web of Conferences. https://doi.org/10.1051/matecconf/201816202006

[8] Vyrides, I., Rakanta, E., Zafeiropoulou, T. and Batis, G. (2013) Efficiency of Amino Alcohols as Corrosion Inhibitors in Reinforced Concrete. Open Journal of Civil Engineering, 3, 1-8. https://doi.org/10.4236/ojce.2013.32A001

[9] Fedrizzi, L., Azzolini, F. and Bonora, P.L. (2005) The Use of Migrating Corrosion Inhibitors to Repair Motorways' Concrete Structures Contaminated by Chlorides. Cement and Concrete Research, 35, 551-561. https://doi.org/10.1016/j.cemconres.2004.05.018

[10] ASTM C1543 (1996) Standard Test Method for Determining The Penetration of Chloride Ion into Concrete by Ponding.

[11] BS EN 12390-8:2000 (2000) Testing Hardened Concrete, Part 8: Depth of Pentration of Water under Pressure.

[12] ASTM (2009) Standard Test Method for Electrical Indication of Concrete's Ability to Resist Chloride.

[13] Papadakis, V.G., Fardis, M.N. and Vayenas, C.G. (1992) Effect of Composition, Environmental Factors and Cement-Lime Mortar Coating on Concrete Carbonation. Materials and Structures, 25, 293-304. https://doi.org/10.1007/BF02472670

[14] Roy, S.K., Poh, K.B. and Northwood, D.O. (1999) Durability of Concrete: Accelerated Carbonation and Weathering Studies. Building and Environment, 34, 597-606. https://doi.org/10.1016/S0360-1323(98)00042-0

[15] EN 13295 (2004) Products and Systems for the Protection and Repair of Concrete Structures-Test Methods-Determination of Resistance to Carbonation.

[16] Chang, C.F. and Chen, J.W. (2006) The Experimental Investigation of Concrete Carbonation Depth. Cement and Concrete Research, 36, 1760-1767. https://doi.org/10.1016/j.cemconres.2004.07.025

[17] Kumar, R. and Bhattacharjee, B. (2004) Assessment of Permeation Quality of Concrete through Mercury Intrusion Porosimetry. Cement and Concrete Research, 34, 321-328. https://doi.org/10.1016/j.cemconres.2003.08.013

[18] Das, B.B. and Kondraivendhan, B. (2012) Implication of Pore Size Distribution Pa- 
rameters on Compressive Strength, Permeability and Hydraulic Diffusivity of Concrete. Construction and Building Materials, 28, 382-386.

https://doi.org/10.1016/j.conbuildmat.2011.08.055

[19] Ma, H. (2014) Mercury Intrusion Porosimetry in Concrete Technology: Tips in Measurement, Pore Structure Parameter Acquisition and Application. Journal of Porous Materials, 21, 207-215. https://doi.org/10.1007/s10934-013-9765-4 